\title{
Regional Sea Level Changes for the Twentieth and the Twenty-First Centuries Induced by the Regional Variability in Greenland Ice Sheet Surface Mass Loss 0
}

\author{
B. MeyssignaC \\ LEGOS, CNES, CNRS, IRD, UPS, Université de Toulouse, Toulouse, France \\ X. FETTWEIS \\ Department of Geography, University of Liege, Liege, Belgium \\ R. CHEVRIER \\ LEGOS, CNES, CNRS, IRD, UPS, Université de Toulouse, Toulouse, France \\ G. SPADA \\ Dipartimento di Scienze Pure e Applicate, Università di Urbino, Urbino, and Istituto Nazionale di \\ Geofisica e Vulcanologia, Sezione di Bologna, Italia
}

(Manuscript received 26 April 2016, in final form 2 November 2016)

\begin{abstract}
Surface mass balance (SMB) variations of the Greenland ice sheet (GrIS) have been identified as an important contributor to contemporary and projected global mean sea level variations, but their impact on the regional sea level change pattern is still poorly known. This study proposes estimates of GrIS SMB over 19002100 based on the output of 32 atmosphere-ocean general circulation models and Earth system models involved in phase 5 of the Climate Model Intercomparison Project (CMIP5). It is based on a downscaling technique calibrated against the Modèle Atmosphérique Régional (MAR) regional climate model and it provides an ensemble of 32 Greenland SMB estimates for each Greenland major drainage basin. Because the GrIS SMB does not respond uniformly to greenhouse gas (GHG) emissions, the southern part of the GrIS is more sensitive to climate warming. This study shows that this part should be in imbalance in the twenty-first century sooner than the northern part. This regional variability significantly affects the associated relative sea level pattern over the entire ocean and particularly along the U.S. East Coast and the northern coast of Europe. This highlights the necessity of taking into account GrIS regional SMB changes to evaluate accurately relative sea level changes in future projections.
\end{abstract}

\section{Introduction}

Contemporary sea level is rising in response to current global warming and is expected to accelerate through the twenty-first century (Church et al. 2013). Mass

Supplemental information related to this paper is available at the Journals Online website: http://dx.doi.org/10.1175/ JCLI-D-16-0337.s1.

Corresponding author e-mail: Benoit Meyssignac, benoit. meyssignac@legos.obs-mip.fr balance variations of the Greenland ice sheet (GrIS) play an important role in these sea level variations. Over the last two decades they explain around $18 \%$ of the contemporary sea level rise, and by the end of the twenty-first century, they are expected to explain $17 \% \pm$ $11 \%$ of the total sea level rise (Church et al. 2013).

Increasing temperatures make the GrIS lose mass both at its surface and on its coastal margins via iceberg discharges and basal melting. Estimates of ice sheet mass loss over the last decade indicate that current GrIS mass loss is equally partitioned between surface loss and dynamical loss (van den Broeke et al. 2009, 2016; Rignot 
et al. 2011). At the coastal margins the recent increased ice loss is caused by acceleration in the flow of outlet glaciers (Rignot et al. 2011). This acceleration is related to two processes: 1) a dynamical response to increased lubrication at the bottom of the ice sheet due to increased surface meltwater reaching the bedrock (Zwally et al. 2002) and 2) an acceleration in the flow of tidewater glaciers due to the reduction of buttressing, caused by thinning or calving of ice (Howat et al. 2007; Nick et al. 2009; Sundal et al. 2013). Recent observations suggest that the lubricating effect may actually play a smaller role than expected because larger amounts of meltwater may form channels beneath the ice that drain the water away more efficiently and reduce the lubricating effect (Nick et al. 2009; Rignot et al. 2011; Shannon et al. 2013; Sundal et al. 2011). In contrast, the iceberg calving effect is a major effect today, but it is expected to decline in the future as outlet glaciers retreat above sea level (Goelzer et al. 2013), letting surface mass balance (SMB) dominate GrIS mass loss by the end of this century.

At the surface, the GrIS surface mass balance can be approximated accurately by the difference between ice mass gained through snowfall accumulation and water mass lost through meltwater runoff in summer. The other terms of the surface budget, which are the mass loss from wind erosion, evaporation, and sublimation and the mass gain from deposition and condensation, are negligible compared to snowfall and meltwater runoff (Box et al. 2004; Lenaerts et al. 2012). Under warmer climate, increased atmospheric temperatures should lead to increased atmospheric moisture content and then to increased precipitation and increased thickening of the ice sheet at high altitude inland (Gregory and Huybrechts 2006; Fettweis et al. 2013a). In the periphery, at low altitude, rising temperatures lead to enhanced surface melting and then to a thinning of the ice sheet. Recent observations (van den Broeke et al. 2009; Fettweis et al. 2011; Rignot et al. 2011) and modeling studies based on atmospheric reanalysis (Fettweis et al. 2008) show that over the last decade increased inland snowfall in winter has not compensated the increased runoff in the ablation area yielding to a significant drop in GrIS surface mass balance (Sasgen et al. 2012; Shepherd et al. 2012; van den Broeke et al. 2016). Modeling studies indicate that in the future, this mass imbalance at the surface should continue and accelerate as the climate warms (Fettweis et al. 2008, 2013a; Gregory and Huybrechts 2006; Rae et al. 2012; Vizcaíno et al. 2014, 2015).

In this context, it is essential to analyze how GrIS meltwater runoff, precipitation, and SMB change with global warming. In this study, we focus on the GrIS SMB

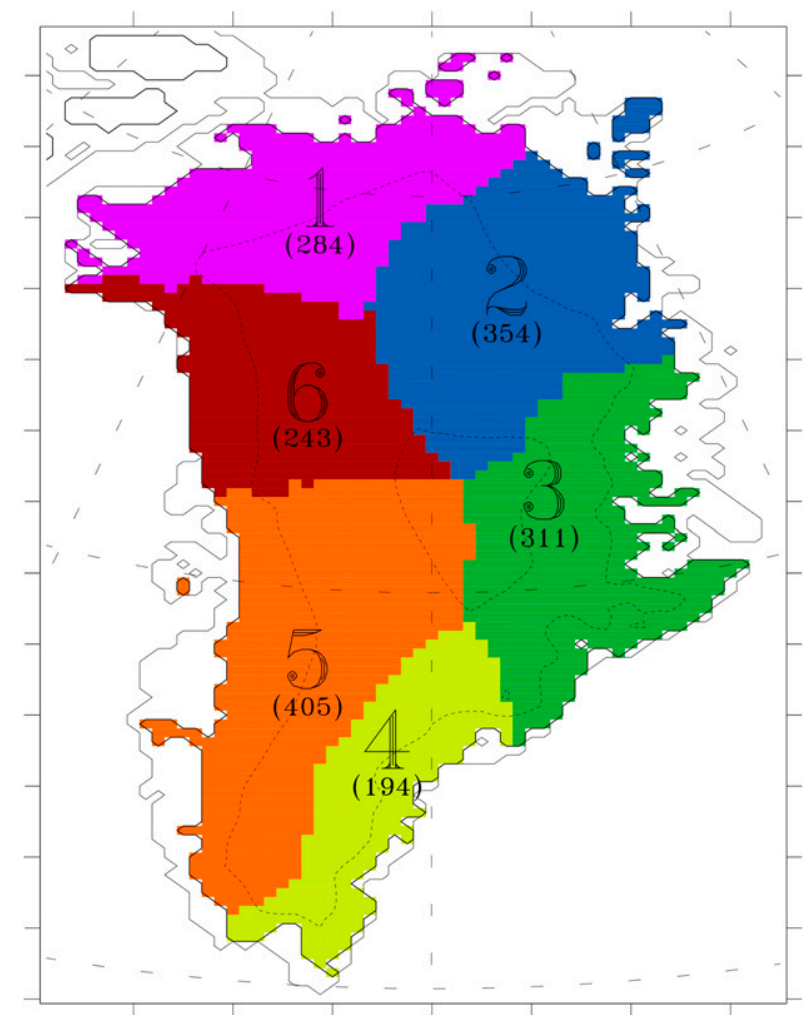

FIG. 1. Map of the Greenland drainage basins as defined in Tedesco and Fettweis (2012). Numbers in parentheses indicate the area of the basin in $10^{3} \mathrm{~km}^{2}$.

over the twentieth and twenty-first centuries. We provide, for the first time, consistent estimates [i.e., computed with the same models over the past (1900-2015) and over the future (2015-2100)] of GrIS SMB over 1900-2100 based on the output of 32 CMIP5 atmosphereocean general circulation models and Earth system models (referred to as GCMs herein). We break down the GrIS SMB estimates into six regional estimates over the six major drainage basins of Greenland (see Fig. 1) to account for the diverse response of different areas of the GrIS to atmosphere and ocean warming (see section 2), as performed in Lenaerts et al. (2015) for studying the impact of GrIS runoff on oceanic circulation. In the absence of long-term observations of GrIS SMB, these estimates are compared to estimates based on outputs from atmospheric reanalyses over the recent decades (see section 3 ). Then we evaluate the regional sea level changes induced by the GrIS SMB changes taking into account its regional variability among the six drainage basins (see section 3). The regional variability in the GrIS SMB yields sizable regional variability in associated sea level changes that was neglected in previous studies and that are discussed (in section 3) before the conclusion. 
TABLE 1. Ensemble of 32 CMIP5 GCM simulations used to force Eq. (3) to get an ensemble of 32 GrIS SMB estimates. The simulations used are the CMIP5 historical runs over 1900-2005 extended until 2100 with RCP8.5 runs. (Expansions of acronyms are available online at http://www.ametsoc.org/PubsAcronymList.)

\begin{tabular}{|c|c|}
\hline Model ID & Institution, country \\
\hline ACCESS1.0 & Centre for Australian Weather and Climate Research, Australia \\
\hline \multicolumn{2}{|r|}{ 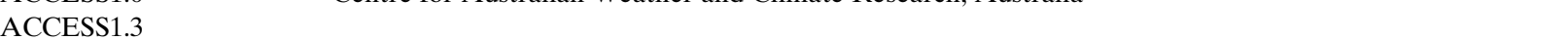 } \\
\hline BCC_CSM1.1 & Beijing Climate Center, China \\
\hline \multicolumn{2}{|l|}{ BCC_CSM1.1(m) } \\
\hline CanESM2 & Canadian Centre for Climate Modelling and Analysis, Canada \\
\hline CCSM4 & National Center for Atmospheric Research, United States \\
\hline \multicolumn{2}{|r|}{ (2) } \\
\hline \multicolumn{2}{|l|}{ CESM1(CAM5) } \\
\hline CNRM-CM5 & Météo-France/Centre National de Recherches Météorologiques, France \\
\hline FIO-ESM & First Institute of Oceanography, China \\
\hline FGOALS-g2 & $\begin{array}{l}\text { National Key Laboratory of Numerical Modeling for Atmospheric Sciences and Geophysical Fluid } \\
\text { Dynamics, China }\end{array}$ \\
\hline GFDL-ESM2M & National Oceanic and Atmospheric Administration/Geophysical Fluid Dynamics Laboratory, United States \\
\hline \multicolumn{2}{|r|}{ - } \\
\hline \multicolumn{2}{|l|}{ GFDL CM3 } \\
\hline GISS-E2-H & National Aeronautics and Space Administration Goddard Institute for Space Studies, United States \\
\hline \multicolumn{2}{|r|}{ 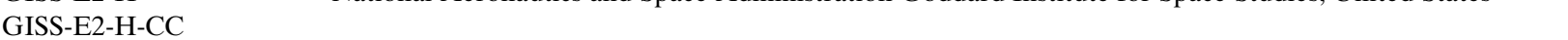 } \\
\hline \multicolumn{2}{|l|}{ GISS-E2-R-CC } \\
\hline \multicolumn{2}{|l|}{ GISS-E2-R } \\
\hline HadGEM2-CC & Met Office Hadley Centre for Climate Prediction and Research, United Kingdom \\
\hline \multicolumn{2}{|r|}{ 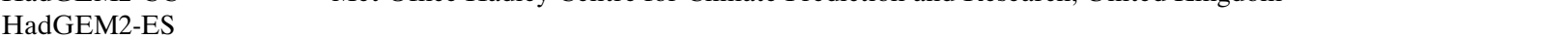 } \\
\hline IPSL-CM5A-LR & L'Institut Pierre-Simon Laplace, France \\
\hline \multicolumn{2}{|l|}{ IPSL-CM5A-MR } \\
\hline \multicolumn{2}{|l|}{ IPSL-CM5B-LR } \\
\hline MIROC5 & University of Tokyo, Japan \\
\hline \multicolumn{2}{|l|}{ MIROC-ESM } \\
\hline \multicolumn{2}{|l|}{ MIROC-ESM-CHEM } \\
\hline MPI-ESM-LR & Max Planck Institute for Meteorology, Germany \\
\hline \multicolumn{2}{|l|}{ MPI-ESM-MR } \\
\hline MRI-CGCM3 & Meteorological Research Institute, Japan \\
\hline \multicolumn{2}{|l|}{ MRI-ESM1 } \\
\hline NorESM1-M & Norwegian Climate Centre, Norway \\
\hline NorESM1-ME & \\
\hline
\end{tabular}

\section{Method}

GCMs have a spatial resolution $(\sim 300 \mathrm{~km})$ that is too coarse to resolve the SMB in the narrow ablation zone of the GrIS (which is a few tens of kilometers wide). In addition, their representation of the snow, ice, and firn processes is not realistic in the upper layer of the snowpack. These shortcomings prevent making any direct estimates of the GrIS SMB from GCM outputs. That is why we use here the high-resolution $(25 \mathrm{~km})$ regional climate model Modèle Atmosphérique Régional (MAR), which has been developed to simulate the GrIS SMB and which has been extensively validated against observations (Fettweis 2007; Fettweis et al. 2005; Franco et al. 2012; Lefebre et al. 2003, 2005). Version 3.5 of MAR (MARv3.5; Colgan et al. 2015) has been used here. We consider simulations of MAR forced at its boundaries by GCM outputs. As explained in Fettweis et al. (2013a), MAR is forced every $6 \mathrm{~h}$ by temperature (at each MAR vertical level), wind, humidity, and surface pressure from the GCM. The sea surface temperature and the sea ice cover from the GCM are also prescribed every $6 \mathrm{~h}$ on the oceanic pixel of MAR. The integration domain is described in Fettweis (2007). We used the same GCM outputs as in Fettweis et al. (2013a), but version 3.5 of MAR is used here while version 2 of MAR (MARv2) was used in Fettweis et al. (2013a). The improvements of MARv3.5 with respect to MARv2 are described in Colgan et al. (2015) and Alexander et al. (2016).

The most straightforward approach to estimate Greenland major drainage basins' SMB from an ensemble of 32 GCMs (see Table 1) is to run 32 MAR simulations of the GrIS SMB forced at boundaries by the 32 GCMs. Unfortunately this is impossible because each MAR simulation with its high resolution and enhanced physics is too computationally expensive. Here we take an alternative approach similar to the downscaling approach of Fettweis et al. (2013a, section 5.3) 
TABLE 2. CMIP5 GCM simulations and atmospheric reanalyses used to force MAR at its boundaries in MAR simulations. MAR simulations forced with GCMs are the four MAR reference simulations. (MAR simulations forced with atmospheric reanalyses are used for validation in Fig. 5.)

\begin{tabular}{llll}
\hline \hline $\begin{array}{l}\text { Model used to force } \\
\text { MAR at boundaries }\end{array}$ & \multicolumn{1}{c}{ Simulation } & \multicolumn{1}{c}{ Institution, country } & $\begin{array}{c}\text { Period of the } \\
\text { simulation }\end{array}$ \\
\hline ERA-40 & Reanalysis & ECMWF, United Kingdom & $1958-78$ \\
ERA-Interim & Reanalysis & ECMWF, United Kingdom & $1979-2014$ \\
CanESM2 & Historical + RCP8.5 & Canadian Centre for Climate Modelling & $1960-2100$ \\
& & and Analysis, Canada & $1950-2100$ \\
NorESM1-M & Historical + RCP8.5 & Norwegian Climate Centre, Norway & $1900-2100$ \\
MIROC5 & Historical + RCP4.5 & University of Tokyo, Japan & $1900-2060$ \\
MIROC5 & Historical + RCP8.5 & University of Tokyo, Japan & \\
\hline
\end{tabular}

but at basin scale as in Lenaerts et al. (2015). We use four reference MAR simulations forced by four different CMIP5 GCM simulations (see Table 2). From these reference simulations, we derive two empirical equations that approximate MAR-based meltwater runoff and snowfall anomalies from the output of the GCM simulations. On the basis of these empirical relations we estimate and analyze regional GrIS meltwater runoff, precipitation, and SMB over 1900-2100 with the outputs of an ensemble of 32 CMIP5 GCMs.

For the four reference simulations we have chosen the climate simulations from the CanESM2, NorESM1-M, and MIROC5 GCMs because they give the best estimate of the current climate over Greenland [in terms of June, July, and August (JJA) mean temperature at $700 \mathrm{hPa}$, annual mean wind speed at $500 \mathrm{hPa}$, and annual mean wind direction at $500 \mathrm{hPa}$ over $1980-99$ in comparison with ERA-Interim; see Fettweis et al. (2013a) for more details]. For 1900-2005, we use the historical scenarios from the CMIP5 project (historical simulations refer to experiments simulating climate change since the mid-nineteenth century by prescribing time-dependent atmospheric composition including anthropogenic GHG and aerosols; Taylor et al. 2012). For 2006-2100 we use both midrange [representative concentration pathway 4.5 (RCP4.5); see Moss et al. (2010) for a description of the RCP scenarios] and high-end (RCP8.5) GHG emission scenarios to ensure that we cover the whole range of temperature that could be experienced by the GrIS until 2100. From the four reference MAR simulations (listed in Table 2) we derive for each of the six Greenland basins 1) a downscaling function of the annual snowfall anomalies based on the GCM annual precipitation anomalies and 2) a downscaling function of the annual meltwater runoff anomalies based on the GCM mean summer temperature anomalies at $600 \mathrm{hPa}\left(\mathrm{T} 600_{\mathrm{JJA}}\right)$. Anomalies are computed with respect to the $1970-89$ period. Then from these relations, we deduce an empirical estimate of Greenland basins SMB based on GCM T600 and precipitation anomalies (see next subsections). As the GCM does not project general circulation changes over
Greenland (Belleflamme et al. 2013), we assume that this empirical GCM-based SMB estimate, which reproduces well the MAR estimates using four GCM simulation outputs as forcing, can be run for all climate model simulations from our ensemble.

\section{a. Empirical estimate of snowfall anomalies}

Figure 2 shows the scatterplots for each Greenland basin of annual snowfall anomalies from MAR against annual precipitation anomalies from the GCM used to force MAR at boundaries. The scatterplots include the four reference MAR simulations forced by GCM simulation outputs (each simulation in a different color; see Fig. 2). They show that the snowfall variability in the northern Greenland basins (basins 1, 2, 3, and 6) as simulated by MAR is mostly driven by the forcing GCM precipitation variability. This is also true for the southern basins (basins 4 and 5) but to a lesser extent as the topography is more rugged in this area. Therefore, the local topography (e.g., inducing Foehn effect) not resolved by the large resolution of the GCMs has only little impact on the interannual precipitation variability simulated by MAR at basin scale. This result suggests that interannual snowfall anomalies over Greenland are rather driven by the large-scale general atmospheric circulation (simulated by the forcing GCM) than by the local circulation (simulated by MAR). It confirms earlier results from Schuenemann and Cassano (2010) and shows that at basin scale MAR annual snowfall anomalies can be directly estimated by the forcing GCM annual precipitation anomalies. Figure 2 also shows that snowfall anomalies estimated by MAR seem to be independent from the GCM used to force MAR except for basin 5 where snowfall anomalies estimated by MAR forced by CanESM2 are slightly smaller than snowfall anomalies estimated by MAR forced with the other GCMs. This result [which is consistent with Fettweis et al. (2013a)] confirms that a common empirical relationship between MAR snowfall anomalies and GCM precipitation can be extracted from the MAR estimates using four GCM simulation outputs as forcing. As this 
Basin 1

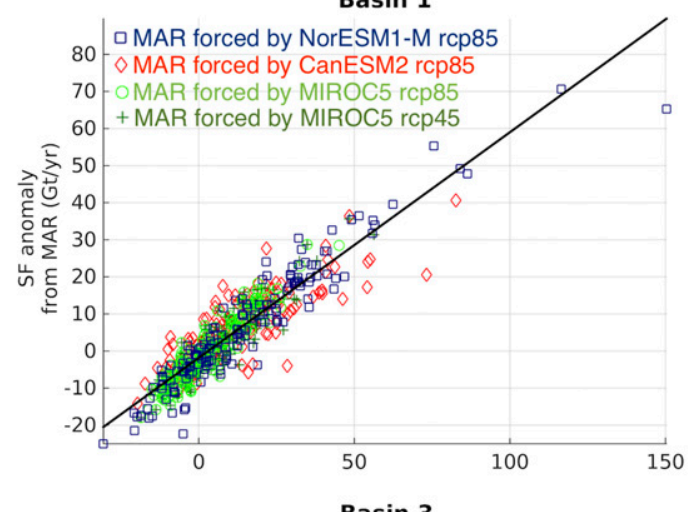

Basin 3
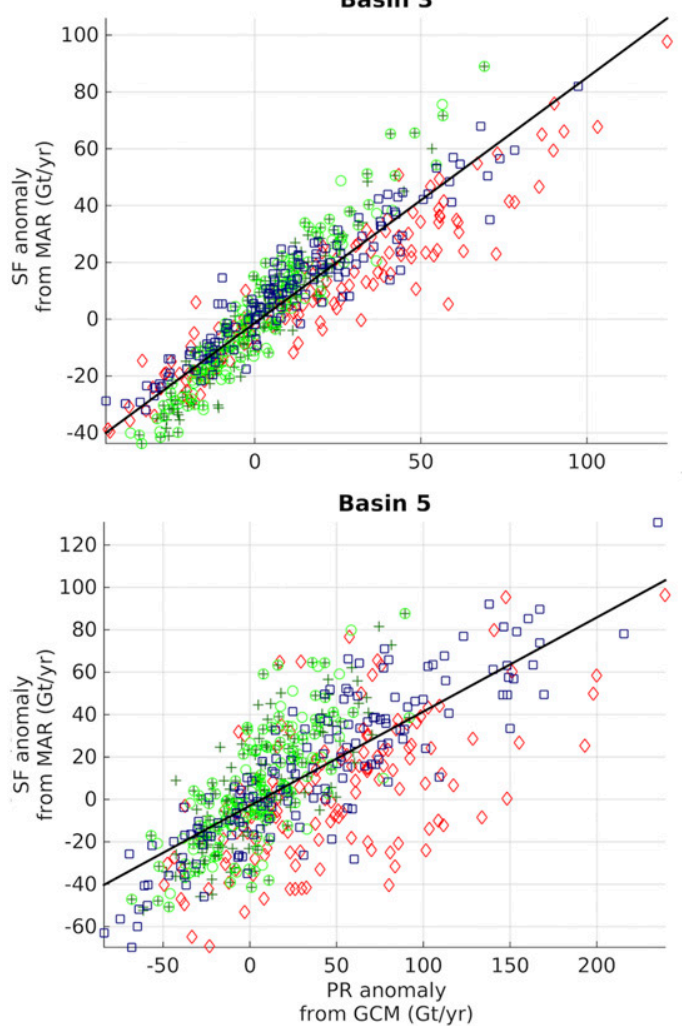

Basin 2

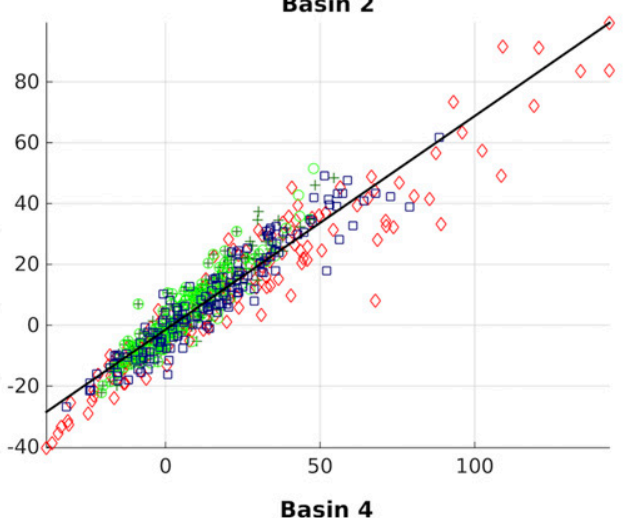

Basin 4

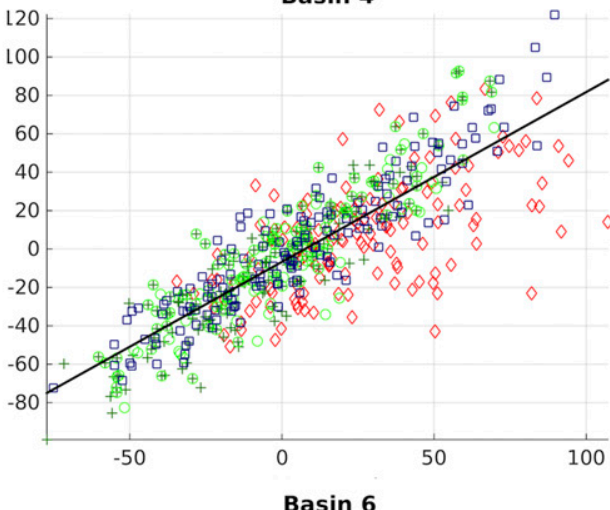

Basin 6

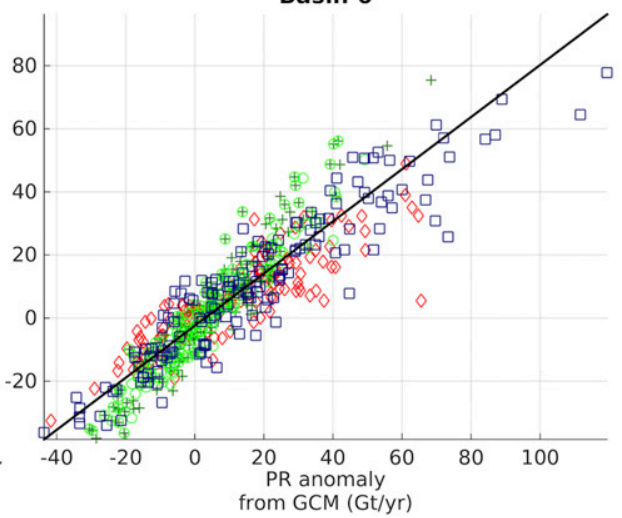

FIG. 2. Annual snowfall anomalies $\left(\mathrm{Gt} \mathrm{yr}^{-1}\right)$ simulated by MAR vs annual precipitation anomalies $\left(\mathrm{Gt} \mathrm{yr}^{-1}\right)$ from the GCMs (different colors) used to force MAR over the MAR simulation periods (see Table 3) for basins 1, 2, 3, 4, 5, and 6. Anomalies are computed with respect to the 1970-89 mean.

relationship is independent from the GCM used to force MAR it can be applied to the 32 climate model simulations of our ensemble.

We test polynomial regressions of increasing order of the scatterplots of Fig. 2. Linear regressions are sufficient to explain more than $70 \%$ of the total variance in the scatterplots of Fig. 2 (regression coefficients are given in Table 3). Higher-order polynomials explain only a few additional percentage points of extra variance over linear regressions and were discarded (see Fig. S1 in the supplemental material). In accordance with the linear regressions [also used by Fettweis et al. (2013a) at the Greenland scale], we approximate the MAR-based snowfall anomalies of each Greenland basin with the following equation:

$$
\Delta \mathrm{SF}=k \Delta \mathrm{PR}_{\mathrm{GCM}}+l,
$$

where $\Delta \mathrm{PR}_{\mathrm{GCM}}$ is the annual precipitation anomalies estimated by GCMs and $k$ and $l$ are constants that depend on Greenland basins (see Table 3). This simple relationship gives a good approximation of MARbased snowfall anomalies for all basins from forcing 
TABLE 3. Mean and standard deviation $\left(\mathrm{Gt} \mathrm{yr}^{-1}\right)$, regression coefficients [see Eqs. (1)-(3)], RMSE (Gt yr $\left.{ }^{-1}\right)$, and correlation (corr) of regressions of scatterplots in Figs. 2-4.

\begin{tabular}{|c|c|c|c|c|}
\hline Basin & Mean $\pm \operatorname{std} \operatorname{dev}\left(\mathrm{Gt} \mathrm{yr}^{-1}\right)$ & $\operatorname{RMSE}\left(\mathrm{Gt} \mathrm{yr}^{-1}\right)$ & Corr & Regression coefficients \\
\hline \multicolumn{4}{|c|}{ Snowfall anomaly } & $k, l$ \\
\hline 1 & $3.5 \pm 11.8$ & 4.7 & 0.92 & $0.60845,-1.8457$ \\
\hline 2 & $7.5 \pm 18.7$ & 6.3 & 0.94 & $0.70217,-1.4559$ \\
\hline 3 & $5.5 \pm 24.4$ & 10.0 & 0.91 & $0.86382,-1.3352$ \\
\hline 4 & $-1.7 \pm 35.1$ & 19.0 & 0.84 & $0.88445,-6.6944$ \\
\hline 5 & $7.2 \pm 31.4$ & 22.5 & 0.70 & $0.44406,-2.9894$ \\
\hline 6 & $5.0 \pm 20.0$ & 8.5 & 0.90 & $0.82635,-2.3868$ \\
\hline \multicolumn{4}{|c|}{ Meltwater runoff anomaly } & $m, n, p$ \\
\hline 1 & $23.1 \pm 43.5$ & 12.0 & 0.96 & $2.5796,4.7547,-2.7978$ \\
\hline 2 & $23.7 \pm 41.5$ & 11.7 & 0.96 & $2.598,4.1822,-0.8324$ \\
\hline 3 & $17.4 \pm 30.1$ & 6.4 & 0.98 & $1.61,5.5976,-0.71187$ \\
\hline 4 & $36.3 \pm 64.8$ & 17.2 & 0.96 & $2.96787,14.815,-2.9734$ \\
\hline 5 & $91.8 \pm 173.3$ & 44.6 & 0.97 & $10.0289,29.3104,-9.777$ \\
\hline 6 & $21.0 \pm 41.4$ & 9.9 & 0.97 & $2.2192,6.392,-3.4825$ \\
\hline \multicolumn{4}{|c|}{ SMB anomaly } & \\
\hline 1 & $-16.7 \pm 35.8$ & 9.6 & 0.85 & \\
\hline 2 & $-14.2 \pm 32.7$ & 11.0 & 0.84 & \\
\hline 3 & $-9.1 \pm 31.1$ & 12.0 & 0.94 & \\
\hline 4 & $-31.0 \pm 63.3$ & 20.7 & 0.90 & \\
\hline 5 & $-68.3 \pm 145.9$ & 39.6 & 0.84 & \\
\hline 6 & $-13.3 \pm 40.5$ & 11.7 & 0.90 & \\
\hline
\end{tabular}

precipitation anomalies (see Figs. S3-S6 in the supplemental material). The correlation coefficients are higher than 0.7 , and the root-mean-square error (RMSE) is below the interannual variability (the RMSE is $\sim 8 \mathrm{Gt} \mathrm{yr}^{-1}$ for basins $1,2,3$, and 6 and $\sim 20 \mathrm{Gt} \mathrm{yr}^{-1}$ for basins 4 and 5 , while the interannual variability is $\sim \pm 18 \mathrm{Gt} \mathrm{yr}^{-1}$ for basins $1,2,3$, and 6 and $\sim \pm 33 \mathrm{Gt} \mathrm{yr}^{-1}$ for basins 4 and 5; see Table 3). However Eq. (1) shows in general a signal of smaller amplitude than the MARbased signal, in particular for basins 4 and 5 (see Figs. S3S6). In basin 4 the signal from Eq. (1) is also markedly less correlated (correlation of 0.70) to the MAR-based signal than in other basins (correlation $>0.84$; see Table 3 ). This is because in basin 4 (and to a lesser extent in basin 5) the precipitation signal variability is driven in part by the rugged-topography-induced local circulation not resolved at the scale of the GCM resolutions (see Figs. S3-S6).

\section{b. Empirical estimate of meltwater runoff anomalies}

Figure 3 shows the scatterplots of annual runoff anomalies from MAR against mean summer temperature anomalies in the free atmosphere from the GCM used to force MAR at its boundaries. Here we choose summer air temperature from GCMs as a predictor of the MAR-based runoff because Fettweis et al. (2013b) showed that summer temperature at $700 \mathrm{hPa}$ over Greenland could be used as a proxy for surface melt. However, as in Fettweis et al. (2013a), we prefer to use
T600 ${ }_{\mathrm{JJA}}$ rather than $700 \mathrm{hPa}$ because in many GCMs, Greenland topography exceeds the $700-\mathrm{hPa}$ vertical level leading to gaps in temperature data at $700 \mathrm{hPa}$. The scatterplots in Fig. 3 confirms the results of Fettweis et al. (2013b) at regional scale. They show that for all Greenland basins, runoff depends mostly on the summer temperature at the base of the free atmosphere over the basins and that this dependence is nonlinear; as temperature increases the runoff tends to increase but at a faster rate. Part of this nonlinear behavior is the result of the surface albedo positive feedback (Franco et al. 2013) due to the extension of the ablation zone (where bare ice appears) as air temperature increases (other feedbacks like the extension of the melting season may also play a role). This result suggests that the runoff variability at basin scale is essentially driven by the large-scale atmospheric temperature rather than by local processes as for Greenland basins snowfall. Another important point in Fig. 3 is that runoff anomalies estimated by MAR seem to be independent from the GCM used to force MAR (as for snowfall anomalies). First, this is because GCMs show essentially a warming of the free atmosphere over Greenland and no significant change in the general atmospheric circulation patterns over Greenland. Second, the four MAR reference simulations show the same melt rate over the present climate, and therefore, for a same temperature anomaly, the melt response is the same. This result confirms that for runoff 

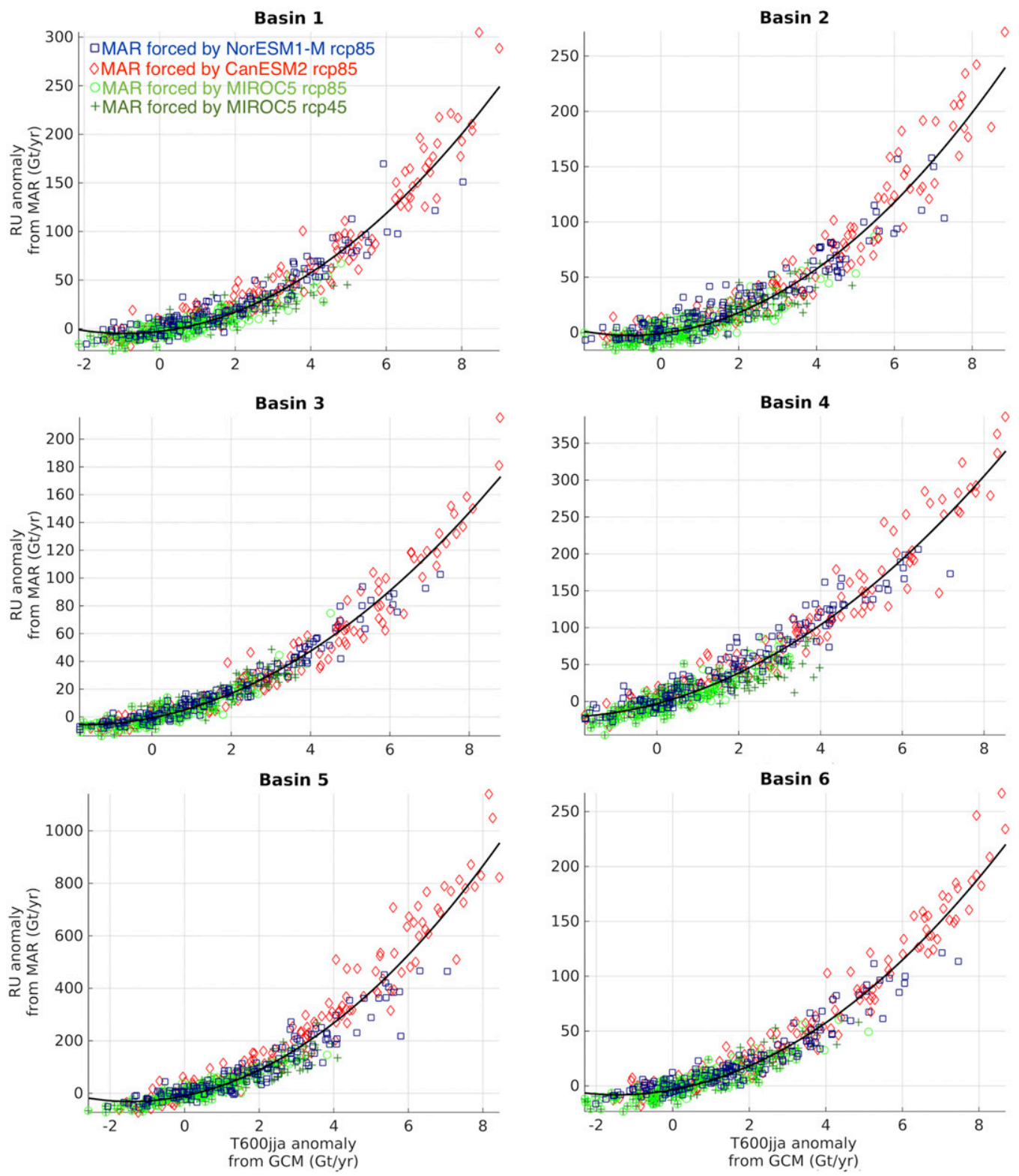

FIG. 3. As in Fig. 2, but for meltwater runoff anomalies $\left(\mathrm{Gt} \mathrm{yr}^{-1}\right)$ vs annual $\mathrm{T} 600_{\mathrm{JJA}}$ anomalies $\left({ }^{\circ} \mathrm{C}\right)$.

anomalies a common empirical relationship between MAR runoff anomalies and GCM T600 JJA can be extracted from Fig. 3 and applied to the 32 climate model simulations of our ensemble.

We test polynomial regressions of increasing order of the scatterplots in Fig. 3. Polynomials of order 2 are necessary to explain more than $95 \%$ of the total variance of the scatterplots in Fig. 3 (regression coefficients are given in Table 3). However, polynomials of order 3 and higher do not explain substantial extra variance (see Fig. S2 in the supplemental material), so we choose a second-order polynomial to approximate MAR-based runoff anomalies from GCM T600 $\mathrm{JJA}_{\mathrm{A}}$ as in Gregory and
Huybrechts (2006). [Note that Fettweis et al. (2013a) found that at the scale of the whole GrIS, a third-order polynomial is a better fit for the MAR-based runoff.] The coefficients of the polynomial have been chosen to best fit (with a least squares procedure) the scatterplots of Fig. 3 and lead to the following relation:

$\Delta \mathrm{RU}=m\left(\Delta \mathrm{T}_{600} 0_{\mathrm{JJA}, \mathrm{GCM}}\right)^{2}+n \Delta \mathrm{T}_{600} 0_{\mathrm{JJA}, \mathrm{GCM}}+p$,

where $\Delta \mathrm{T}_{600} \mathrm{JJA}, \mathrm{GCM}$ represents anomalies in $\mathrm{T} 600_{\mathrm{JJA}}$ estimated by GCMs and $m, n$, and $p$ are constants that depend on the six GrIS basins (see Table 3). Equation (2) gives a very good approximation of MAR-based 
meltwater runoff anomalies for all basins (see Figs. S7S10 in the supplemental material). The correlation coefficients are higher than 0.9 and the RMSE is below the interannual variability (the RMSE is $\sim 12 \mathrm{Gt} \mathrm{yr}^{-1}$ for basins $1,2,3,4$, and 6 and $\sim 45 \mathrm{Gt} \mathrm{yr}^{-1}$ for basin 5 , while the interannual variability is $\sim \pm 45 \mathrm{Gt} \mathrm{yr}^{-1}$ for basins 1 , 2, 3, 4, and 6 and $\sim \pm 173 \mathrm{Gt} \mathrm{yr}^{-1}$ for basin 5; see Table 3). Note, however, that Eq. (2) tends to underestimate slightly the amplitude of the meltwater runoff interannual variability compared to the MAR-based estimate (see Figs. S7-S10). This is because Eq. (2) smooths the extreme melt events resulting from a nonlinear combination of positive feedback amplifying or significantly reducing the melt. The role of rainfall (amplifying the melt) or snowfall (increasing temporally the albedo and thus decreasing the melt) events in summer is not taken into account in Eq. (2) (Noel et al. 2015). The melt rate also depends on the snowpack history (i.e., the warmer the previous summer has been, the higher the melt is when the previous melting snowpack appears at surface), which is not taken into account in Eq. (2).

\section{c. Empirical estimate of SMB anomalies}

From the empirical estimate of snowfall anomalies and meltwater runoff anomalies over the Greenland basins we derive an estimate of the SMB. We sum Eqs. (1) and (2) to get the following SMB empirical estimate:

$$
\begin{aligned}
\Delta \mathrm{SMB}= & k \Delta \mathrm{PR}_{\mathrm{GCM}}-m\left(\Delta \mathrm{T}_{600} 0_{\mathrm{JJA}, \mathrm{GCM}}\right)^{2} \\
& -n \Delta \mathrm{T}_{600} 0_{\mathrm{JJA}, \mathrm{GCM}}+l-p,
\end{aligned}
$$

where $k, l, m, n$, and $p$ are constants that depend on the Greenland basins (see Table 3). Both snowfall anomalies and runoff anomalies play an important role in the Greenland basins SMB temporal variability (cf. the range of the $y$ axis in Figs. 2 and 3). However, as the climate warms the runoff contribution tends to significantly exceed the snowfall contribution for all basins (cf. the meltwater runoff rates under high temperature in Fig. 3 with snowfall rates of Fig. 2). This effect is particularly intense in basin 5 because basin 5 is affected by warm air advection from the southwest in response to the general atmospheric circulation flowing from southwest to northeast over Greenland (Fettweis et al. 2013a) and because the summer surface temperature in this basin is already near the melting point under the current climate (see sections 3 and 4).

To check the ability of Eq. (3) to reproduce Greenland basins SMB, we plot in Fig. 4 the SMB calculated with Eq. (3) against the MAR-based SMB. Figure 4 shows the results for Eq. (3) and the MAR reference simulation forced by MIROC5 historical and RCP4.5 scenario. Similar plots with Eq. (3) and MAR forced with the other GCM reference simulations are given in the supplemental material (see Figs. S11-S13 in the supplemental material). For all reference simulations, Eq. (3)'s SMB estimate is very close to the MAR-based SMB estimate. This is true for all basins, including basins 4 and 5, for which the snowfall estimate from Eq. (1) underestimates the variability of the MAR-based estimate (see Figs. S3-S6 and Table 3). The reason for this is that in basins 4 and 5 runoff anomalies are large and dominate the local SMB signal, in particular in the twenty-first century. For all basins the RMSE of the SMB estimate is below $40 \mathrm{Gt} \mathrm{yr}^{-1}$ (which is smaller than the interannual variability) and the correlation coefficients are higher than 0.84 (see Table 3). Most of the RMSE is coming from differences at interannual time scales. Such agreement gives confidence in the Greenland basins SMB estimate with Eq. (3). However, note that Eq. (3) can only be used to estimate Greenland SMB at basin scale, and it should not be used to estimate Greenland SMB at finer spatial scales.

\section{Results and discussion}

\section{a. Greenland basins SMB in the twentieth century}

We now estimate an ensemble of 32 Greenland basins' SMB over 1900-2100 by forcing Eq. (3) with Greenland precipitation anomalies and $\mathrm{T} 600_{\mathrm{JJA}}$ from an ensemble of 32 GCM simulations (Fig. 5; see Table 1 for a list of GCMs). The GCM simulations are CMIP5 twentieth-century climate simulations extended over the twenty-first century with scenario RCP8.5 simulations. Over 1958-2014 we compare the ensemble of Greenland SMB estimates with an estimate based on MAR forced with ERA-40 (for the period 1958-78; Uppala et al. 2005) and forced with ERA-Interim (for the period 1979-2014; Dee et al. 2011; see Table 2). Estimates based on MAR forced with ERA-40 and ERA-Interim are expressed in anomalies with respect to the mean over the reference period $1970-89$ as for the GCM-based estimates.

Over the twentieth century, the ensemble mean of Greenland SMB estimates is stable in all basins except in basin 5 where it has decreased continuously since 1958 at a small rate of $-0.51 \pm 0.11 \mathrm{Gt} \mathrm{yr}^{-2}$ (see Table 4). For all basins the spread in SMB around the ensemble mean is small in the twentieth century and below the interannual to multidecadal variability in SMB (see Table 4), which suggests that the internal climate variability explains most of this spread across models. The continuous decrease in SMB of basin 5 over 1950-2014 is due to increasing runoff anomalies that exceed the increasing 

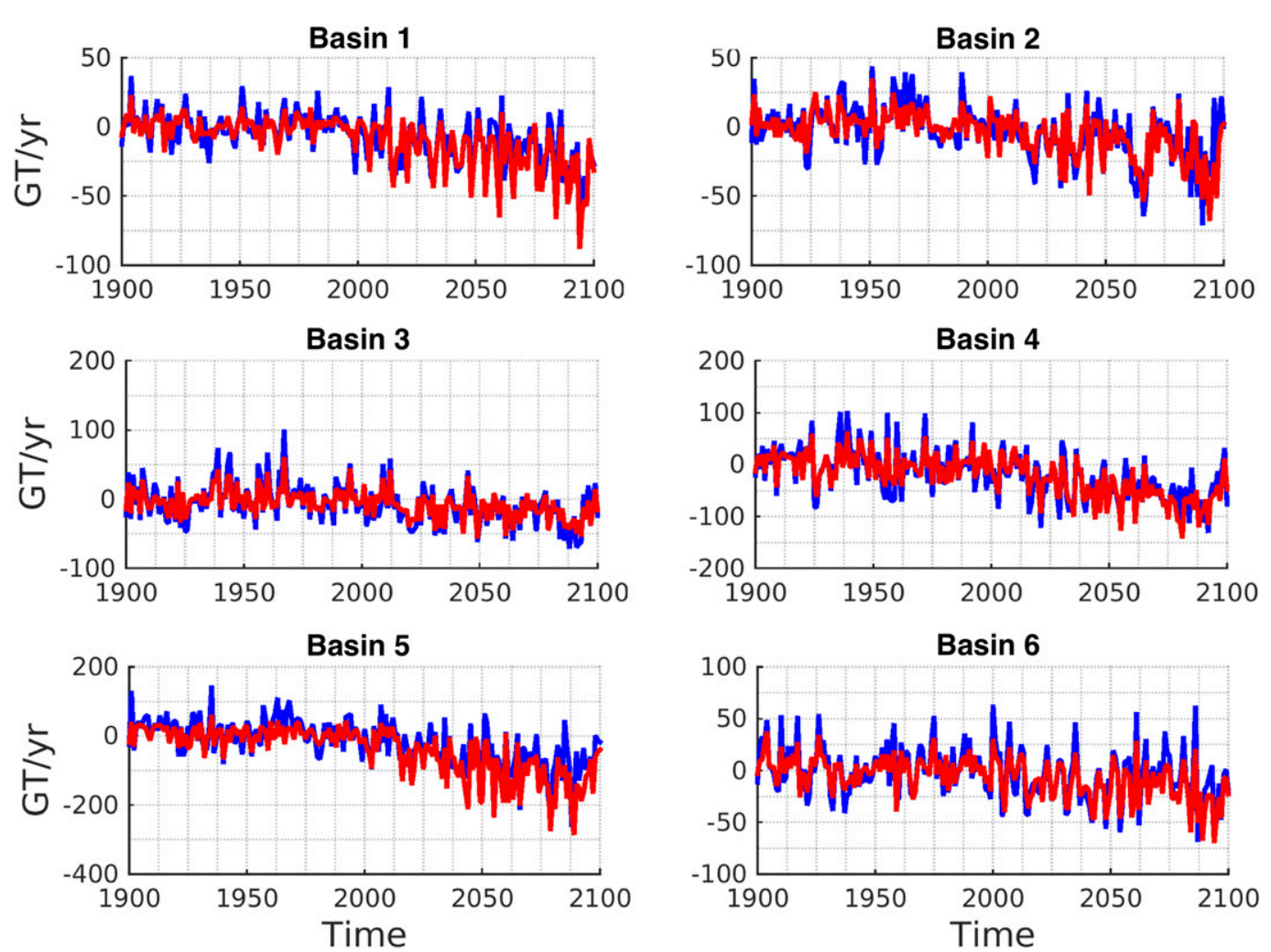

FIG. 4. Annual SMB anomalies ( $\mathrm{Gt} \mathrm{yr}^{-1}$ ) simulated by Eq. (3) (red line) and by MAR (blue line) for basins 1, 2, 3, 4, 5, and 6. Both Eq. (3) and MAR have been forced by MIROC5 historical and RCP4.5 simulations over 19002100 .

snowfall anomalies throughout the second half of the century (see Figs. S14 and S15 in the supplemental material). The fact that the ensemble mean of SMB estimates shows this decrease suggests that it is an early forced response to greenhouse gases or other external forcing. However, this signal is small and could possibly be caused by some multidecadal internal climate variability in GCMs. More investigation is needed to answer this question.

The comparison of the ensemble of Greenland SMB estimates with the estimate based on MAR forced with ERA-40 and ERA-Interim shows that the recent Greenland SMB variations lie within the spread of the ensemble estimates for all basins except basin 1. For basin 1, GCM-based estimates fail to reproduce the large interannual to decadal variability in SMB since 1958 (see Table 4) and particularly after 1997. This is partly because they underestimate the runoff increase resulting from the general circulation changes in summer (not properly projected by GCMs; Belleflamme et al. 2013) favoring advection of warm air from the south (Fettweis et al. 2013b).

The reanalysis-based estimates show positive anomalies of the SMB in the 1970s and the 1980s for basins 1,2, and 6 and to a smaller extent for basin 4. These anomalies are due to the combination of anomalous cold summers and wet years during these periods (Fettweis et al. 2008; Hanna et al. 2008) not reproduced by the GCM ensemble estimate. Note that the anomalous warm summers and dry years of the 1930s, which resulted in large SMB loss rates in Greenland (Chylek et al. 2006; Fettweis et al. 2008; Hanna et al. 2008), are not reproduced here by the GCM ensemble estimate either, suggesting that this major event may have been generated by the internal climate variability as well. After 1990, the reanalysis-based estimate shows a decrease of the SMB in all basins. The GCM ensemble estimate also shows a decrease of the SMB in all basins after 1990, suggesting that the external forcing of the climate system may play a role in the observed decrease of the SMB. It is probably the GHG emissions forcing that is responsible here because the SMB decreasing signal persists and accelerates through the twenty-first century in the GCM ensemble estimate. After 2005, the ERA-based SMB estimate decreases further and departs notably from the GCM ensemble mean estimate in basins 1, 4, 5, and 6. Part of this increased SMB loss is generated by the internal climate variability as a 

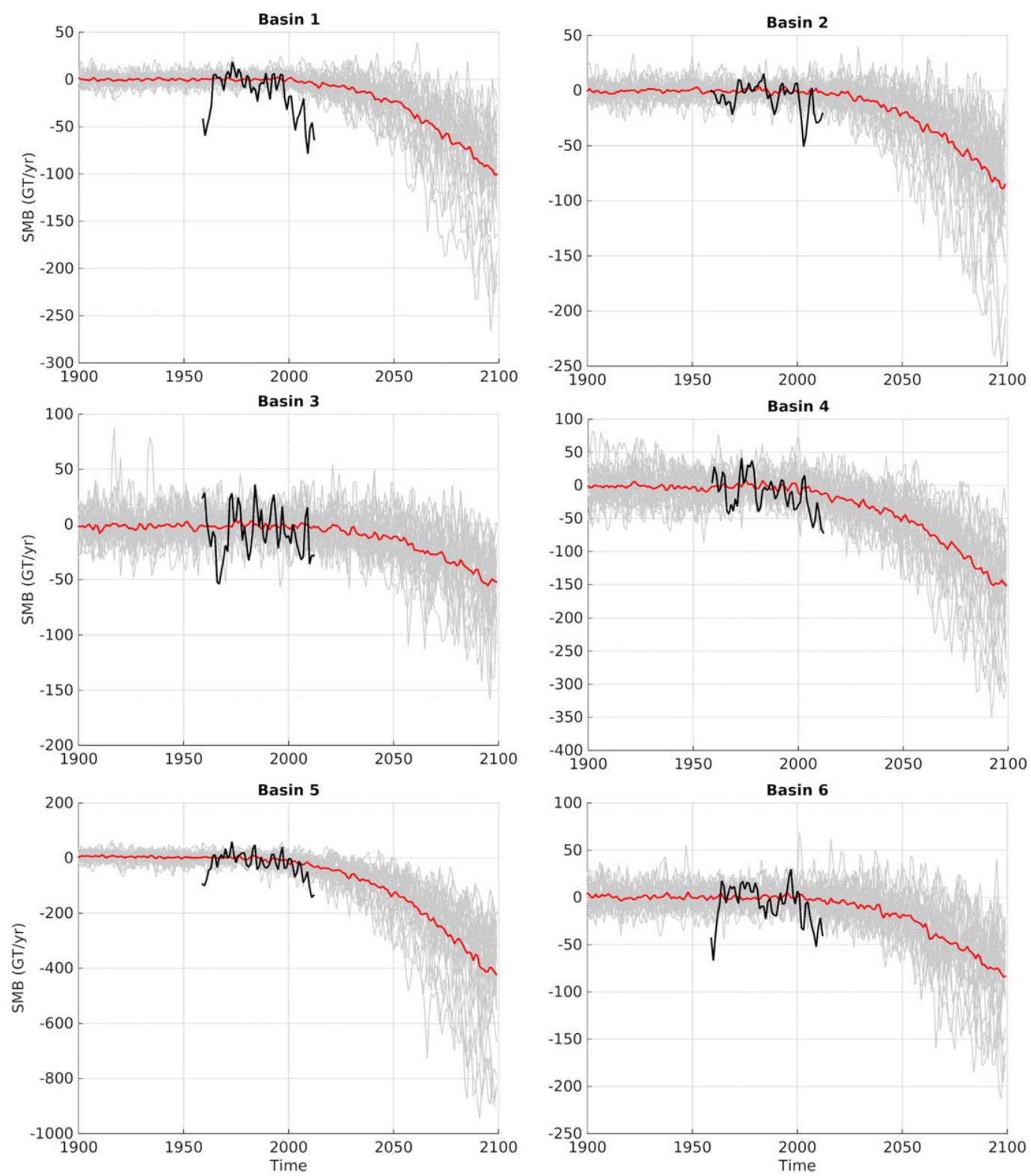

FIG. 5. Annual SMB anomalies $\left(\mathrm{Gt} \mathrm{yr}^{-1}\right)$ simulated by Eq. (3) forced with an ensemble of $32 \mathrm{GCM}$ simulations (individual model simulations are in gray and the ensemble mean is the red line) for basins 1,2,3, 4, 5, and 6. Annual SMB anomalies from MAR forced with ERA-40 and ERA-Interim are in black. Anomalies are calculated w.r.t the mean over 1970-89.

response to the recent sequence of negative phases of the North Atlantic Oscillation in 2007-12, which favored warmer atmospheric conditions than normal over the GrIS (Fettweis et al. 2013b).

\section{b. Greenland basins SMB in the twenty-first century}

For the twenty-first century the picture is different than for the twentieth century. The ensemble mean of the Greenland SMB estimate is decreasing significantly over all basins. The spread around the ensemble mean is larger in the twenty-first century than in the twentieth century, and it grows larger toward the end of the twenty-first century [one standard deviation $(1 \sigma) \approx$ $30 \mathrm{Gt} \mathrm{yr}^{-1}$ for basins $1,2,3,4,6$, and $1 \sigma=137 \mathrm{Gt} \mathrm{yr}^{-1}$ for basin 5 in 2001-2100, assuming a Gaussian distribution around the mean; see Table 4]. In general over 20002100 the spread across GCM-based SMB estimates is larger than the interannual to multidecadal variability of any SMB estimate based on individual GCM simulation. It means that the spread in twenty-first-century SMB 
estimates is dominated by the spread in Greenland climate sensitivity to greenhouse gases across GCMs rather than the spread due to internal climate variability.

The increased SMB loss projected in the twenty-first century is the result of increased runoff anomalies that largely exceed the increased snowfall anomalies as the climate warms (see Figs. S14 and S15). The GCMs that project the warmest climate over Greenland also project the highest runoff anomalies and the largest Greenland SMB loss rates. Basin 5 is the basin that shows the highest SMB loss rates in Greenland, confirming earlier results from Tedesco and Fettweis (2012). In 2081-2100, the SMB loss rate in basin 5 is expected to be much higher than in other basins (see Table 4) and should reach $-364.9 \pm 159 \mathrm{Gt} \mathrm{yr}^{-1}$ (the uncertainty represents the spread around the ensemble mean at $1 \sigma$, assuming a Gaussian distribution), explaining up to $47 \%$ of the Greenland total SMB anomaly. This is because basin 5 is exposed to warm air advection from the ocean transported by the mean circulation flowing from southwest to northeast of Greenland. Basin 4 shows the secondhighest SMB loss rates in the twenty-first century (see Table 4). In this basin the increase in SMB loss rate is essentially caused by an increase in runoff anomalies with a significant contribution from rainfall while the snowfall anomalies are small. Basins 1,2, and 6 tend to show similar SMB loss rates, while basin 3 shows the smallest SMB loss rates (see Table 4), confirming the results from Tedesco and Fettweis (2012). In basins 1, 2, 3 , and 6 increased snowfall anomalies play an important role in dampening the increased runoff anomalies and attenuate the SMB loss rates (see Figs. S14 and S15).

\section{c. Regional sea level changes in response to Greenland SMB changes}

As Greenland surface ice melts, water mass is transferred from GrIS drainage basins to the ocean. This mass redistribution 1) perturbs the gravitational field of Earth, 2) deforms Earth's crust and the solid sea bottom (also perturbing the gravitational field), and 3) changes the orientation and rate of Earth's rotation (Mitrovica et al. 2001). These three processes affect relative sea level (RSL; defined as the elevation of the sea surface above the sea bottom) and make it deviate substantially from the global mean RSL (Gomez et al. 2010; Milne et al. 2009; Mitrovica et al. 2009; Tamisiea and Mitrovica 2011). The regional departures of RSL from the global mean depend on the location of the ice melt and thus depend on the regional variability of the GrIS SMB. Note that dynamical ice discharge also causes water mass transfers from GrIS to the ocean and affects sea level regional variability, but this term is not considered here. In addition, the freshwater fluxes into the ocean 
associated with Greenland ice loss change the ocean circulation (Luo et al. 2016; Lenaerts et al. 2015) and generate regional variability in RSL as well (Kopp et al. 2010; Stammer 2008), but this aspect is not addressed in this study either.

For each member of the ensemble of 32 Greenland SMB estimates based on GCM outputs, we estimate the regional sea level change pattern induced by the GrIS SMB by solving the sea level equation (SLE), originally proposed by Farrell and Clark (1976) to describe the sea level changes induced by the melting of the ice sheets. The SLE is solved numerically using an updated version (Spada et al. 2012) of the sea level equation solver (SELEN; Spada and Stocchi 2007). Since here we study the Greenland SMB on time scales much shorter than the Maxwell relaxation time of the mantle (a few $10^{3} \mathrm{yr}$ ), SELEN is run assuming a layered elastic Earth model, taking into account Earth's compressibility. The elastic model and the density profile are consistent with the preliminary reference Earth model of Dziewonski and Anderson (1981). The effects of Earth rotation on sea level change are modeled following the theory illustrated in Milne and Mitrovica (1998). In solving the SLE, the fixed-shorelines approximation has been adopted, and we have assumed that the ice mass loss is uniformly distributed over each drainage basin.

Figures $6 \mathrm{a}, \mathrm{b}$ show the ensemble mean and the ensemble spread of the RSL change pattern in 2080-99 with respect to 1900-19 of the ensemble of 32 GCMbased Greenland SMB estimates (the RSL change pattern of each member is shown in Fig. S16 of the supplemental material). In 2080-99, all members of the ensemble show a substantial increase in sea level of a few centimeters in most of the ocean far from Greenland and a large decrease in sea level of a few tens of centimeters to one meter close to the coast of Greenland (see Fig. 6a and Fig. S16). The increase in sea level far from Greenland is essentially due to the redistribution of the water loss from Greenland into the ocean. In contrast, the large decrease in sea level close to the coast of Greenland is essentially a response to the decrease in the local geoid due to the mass removal from Greenland (with a small contribution as well from the elastic rebound of Greenland). Figure $6 \mathrm{~b}$ shows that the spread in RSL pattern is not negligible compared to the ensemble mean signal even in regions far from the GrIS. Indeed, ensemble members generally agree on showing a drop in sea level close to the GrIS and sea level rise far from the GrIS, but they differ substantially in the details. Most members show a drop in sea level centered around the south of Greenland and sea level rise off the northern coast of Greenland while members with the highest total GrIS SMB decrease over 1900-2100 tend to show a large drop in sea level occurring all around Greenland (see Fig. 6b and Fig. S16). Some members (like the members forced with the ACCESS, HadGEM2, IPSL, and MIROC GCMs; see Fig. S16) also show a significant sea level rise pattern of $10-20 \mathrm{~cm}$ around South America and in the North Pacific. This pattern is characteristic of changes of degree 2 order 1 of the gravity field and is due to changes in Earth axis orientation.

To evaluate to what extent the regional variability in GrIS SMB over the twentieth and twenty-first centuries affects the RSL patterns we compare our RSL patterns with RSL patterns obtained assuming a uniform distribution over the GrIS of the total Greenland SMB changes. This shows the same RSL pattern for all ensemble members but with different amplitudes [as in the IPCC Fifth Assessment Report (AR5); Church et al. 2013]. This is because the response of the solid Earth to Greenland ice melt is elastic at the centennial time scales, and thus the sea level pattern does not change with the amplitude in ice mass loss (only differences in the distribution of ice mass loss can cause differences in the sea level pattern when Earth response is elastic). Figures $7 \mathrm{a}, \mathrm{b}$ show the ensemble mean and spread of the difference between our RSL patterns and the RSL patterns obtained with the assumption of a uniform distribution of the total SMB over the whole GrIS. They indicate the amplitude in the sea level signal that depends on the geographical distribution of GrIS mass loss. Figure 7a shows that the regional differences between both ensemble mean RSL patterns are large close to the GrIS. In this region the regional variability in the GrIS SMB explains between $20 \%$ and $60 \%$ of the RSL signal. Far from the GrIS the differences are smaller but still sizable, and the regional variability in the GrIS SMB accounts for $10 \%-20 \%$ (in all oceanic regions located more than $3000 \mathrm{~km}$ from Greenland) of the total RSL signal. The differences are important in the near field, like along the east coast of North America and the north coast of Europe. In this region, the total RSL changes are small (a few centimeters; see Fig. 6a) but the regional variability in GrIS SMB plays a significant role in the RSL (Fig. 7a). For the ensemble mean, the inclusion of the regional variability in GrIS SMB changes the RSL in 2080-2100 along the U.S. East Coast and the north coast of Europe by up to $40 \%$ (Fig. $7 \mathrm{a}$ ).

The previous results show that it is important to take into account the regional variability in GrIS SMB to estimate the RSL, but they give no information on the level of resolution in Greenland SMB regional variability that is needed to get accurate RSL estimates. To answer this question, we use the reference MAR simulation forced with the MIROC5 RCP4.5 simulation, which covers the whole period 1900-2100. The MAR 

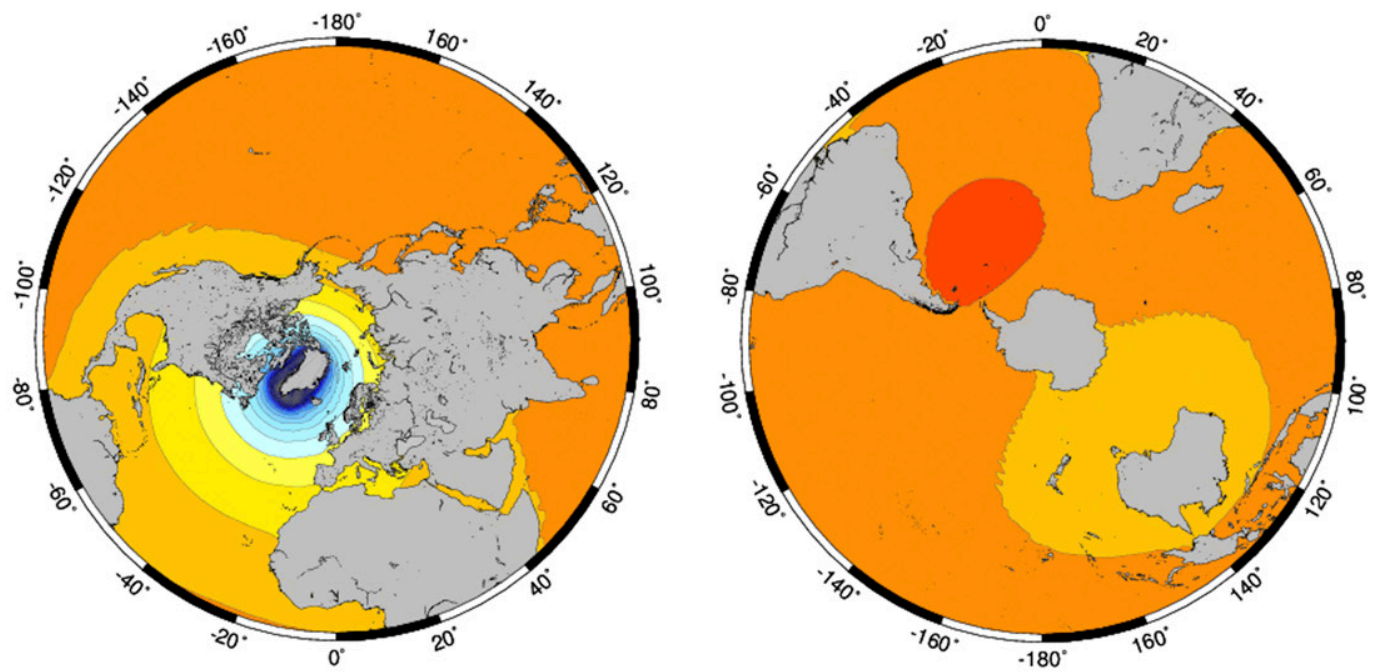

a)
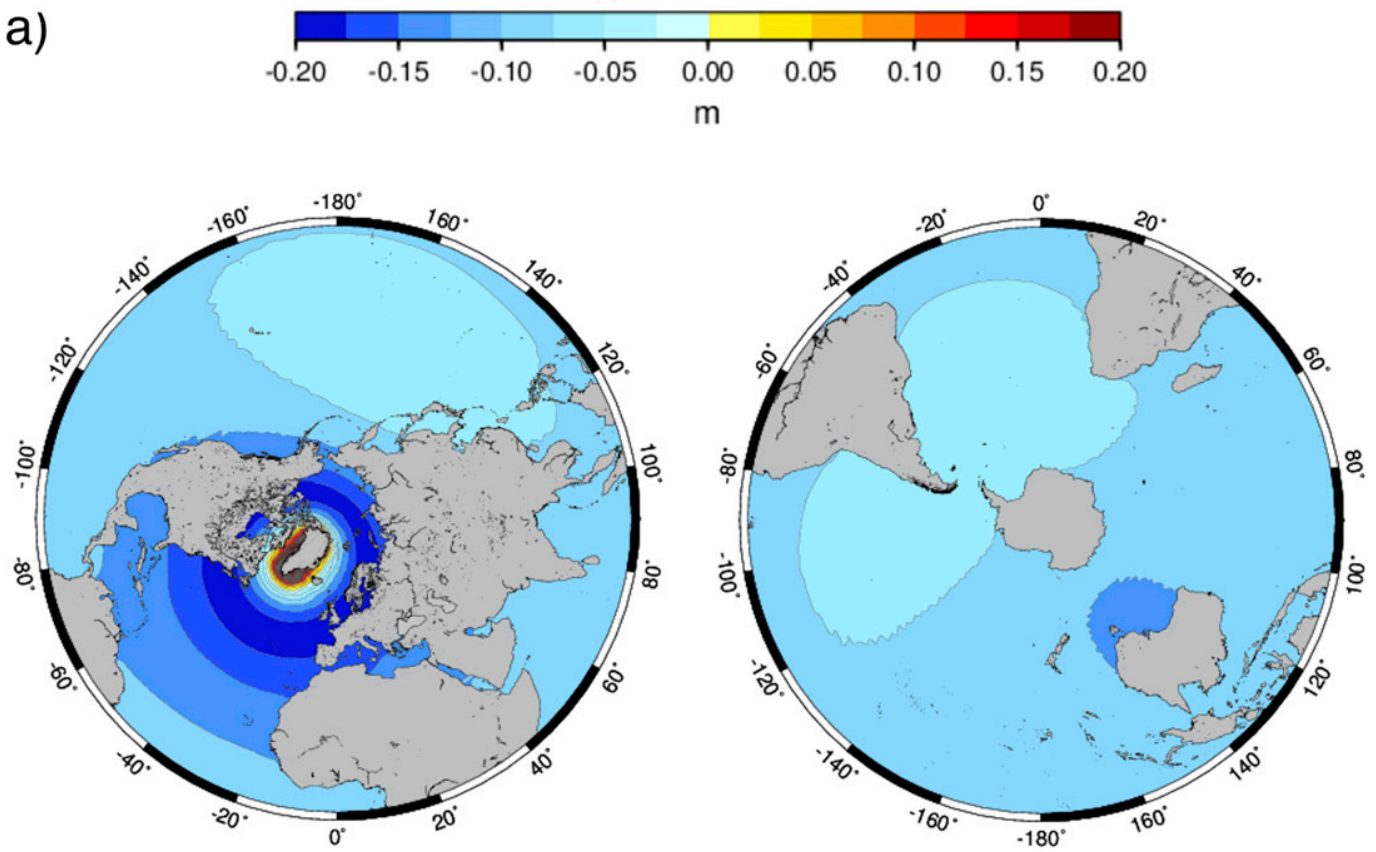

b)

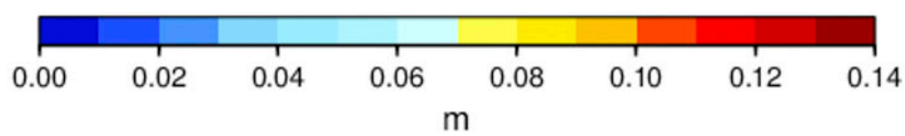

FIG. 6. (a) Ensemble mean and (b) standard deviation of the regional relative sea level changes over 2080-99 (w.r.t. 1900-19) in response to Greenland SMB as estimated by the regional downscaling technique forced by GCMs outputs (see text): (left) Northern and (right) Southern Hemisphere. The regional sea level patterns of (a),(b) include the effect of the regional variability in Greenland SMB changes.

simulation estimate of the Greenland SMB is interpolated at three different resolutions: 1) the SMB is interpolated at $1^{\circ}$ resolution, 2) the SMB is averaged over each drainage basin and then uniformly distributed over the same drainage basin (like in the downscaling technique), and 3) the SMB is averaged over the GrIS and then uniformly distributed over the GrIS. Figure 8a shows the difference in RSL pattern in 2080-2100 (with respect to 1900-19) between the RSL obtained with a regional SMB averaged at basin scale and the RSL 

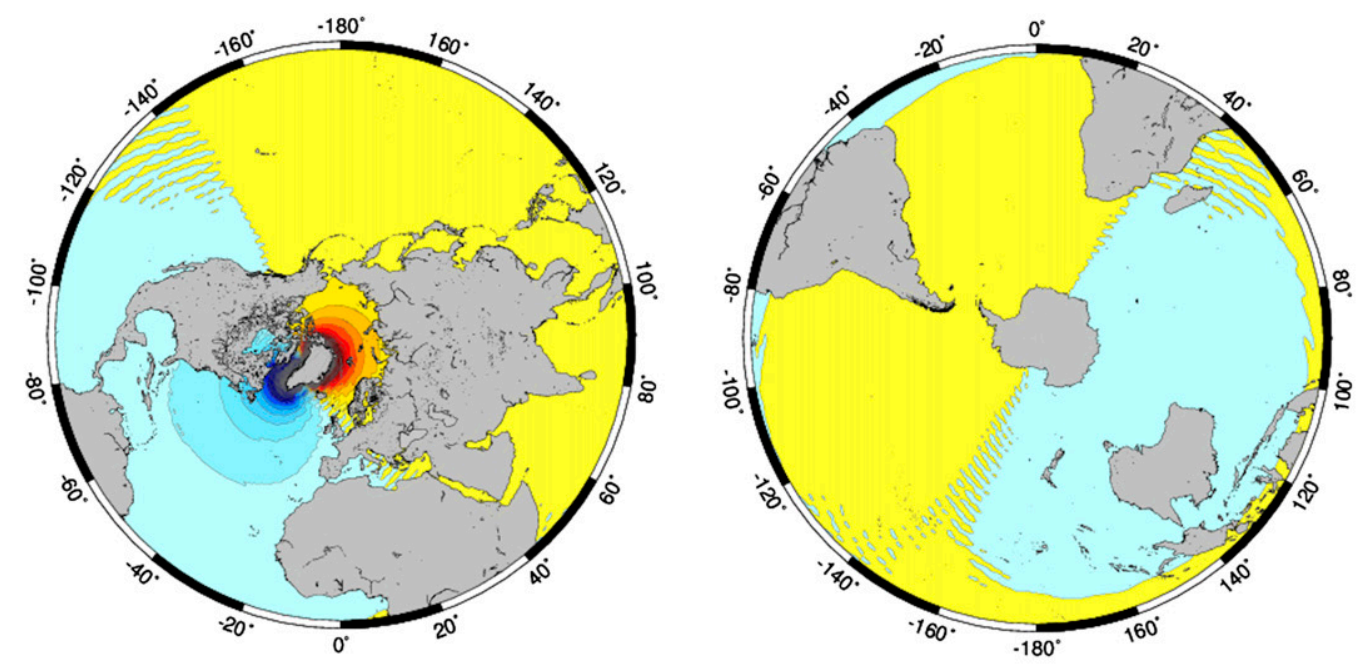

a)
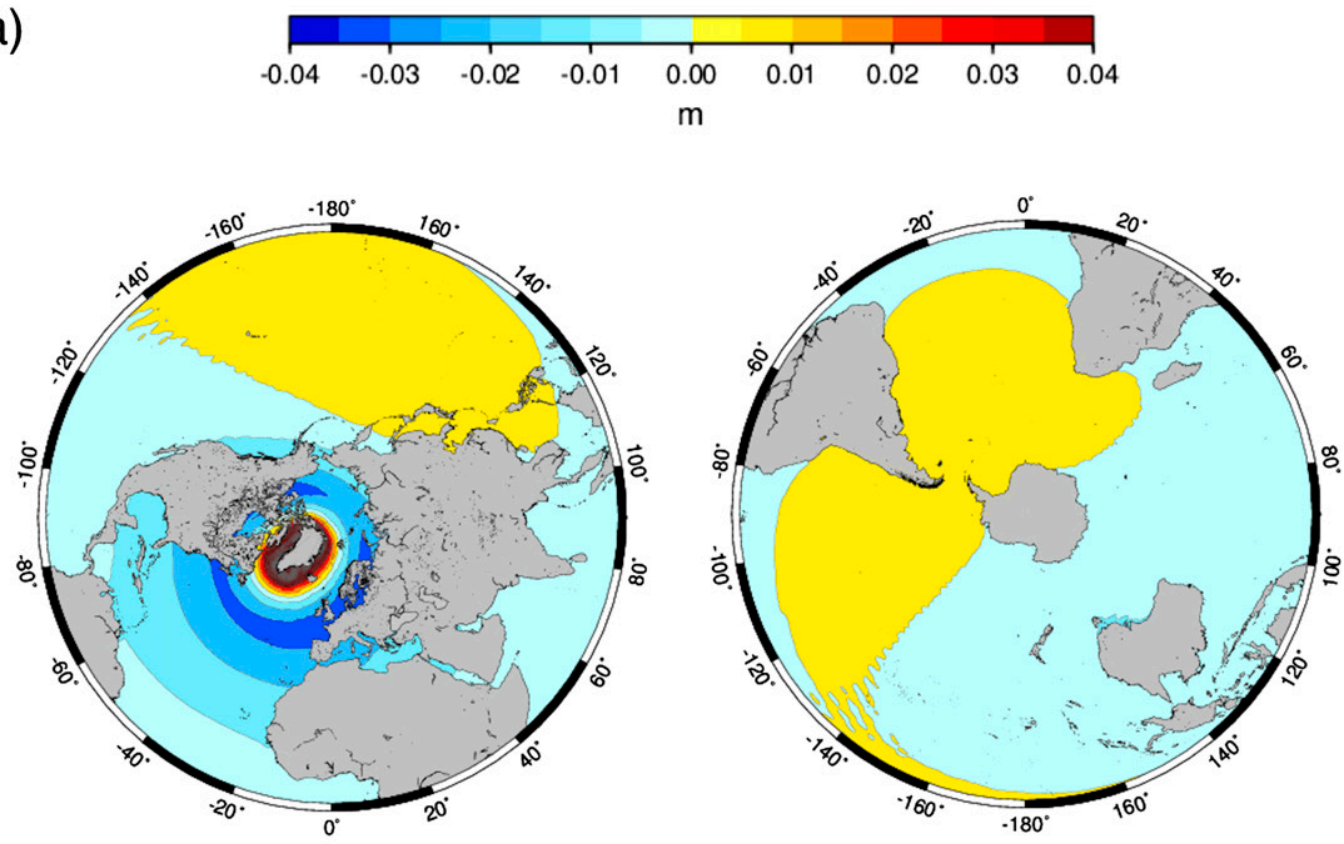

b)

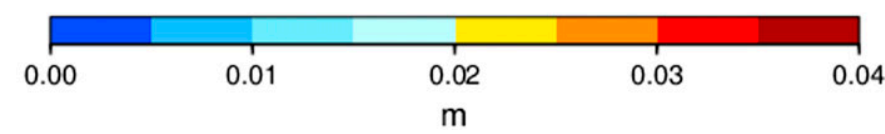

FIG. 7. As in Fig. 6, but due to the regional variability in the Greenland SMB changes only.

obtained with a SMB uniformly distributed over the GrIS. In Fig. 8 b the difference in RSL between the RSL obtained with a regional SMB interpolated at $1^{\circ}$ resolution and the RSL obtained with a regional SMB averaged at basin scale is significantly smaller than in Fig. 8a. For most of the ocean and the coast, taking into account the regional variability in Greenland SMB at $1^{\circ}$ resolution only changes the RSL by $5 \%$ compared to the solution with basin-scale regional variability. Only the Arctic Ocean shows high differences. Some differences can be seen as well in a small band that crosses the United States and European northern coast in the near field, but in this region the RSL values are very small and the differences only amount to a few millimeters.

\section{Conclusions}

We have developed a downscaling technique calibrated against the MAR regional climate model in order to calculate an ensemble of 32 Greenland SMB estimates 

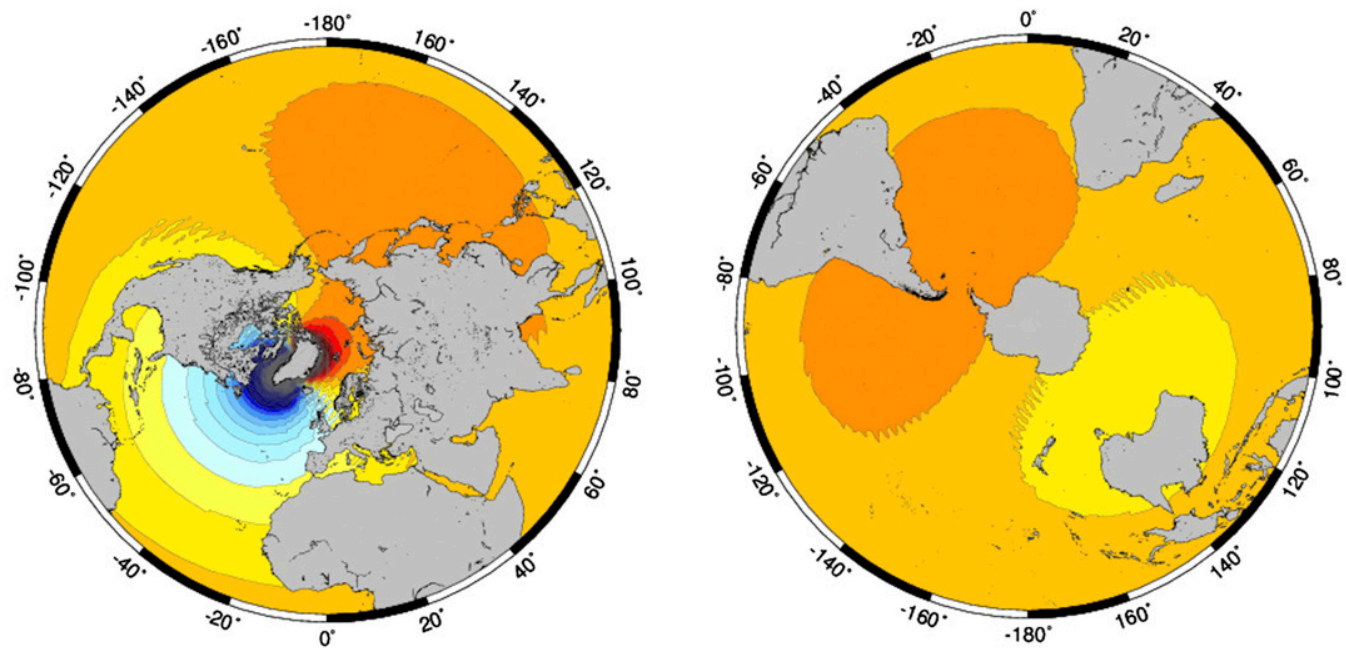

a)
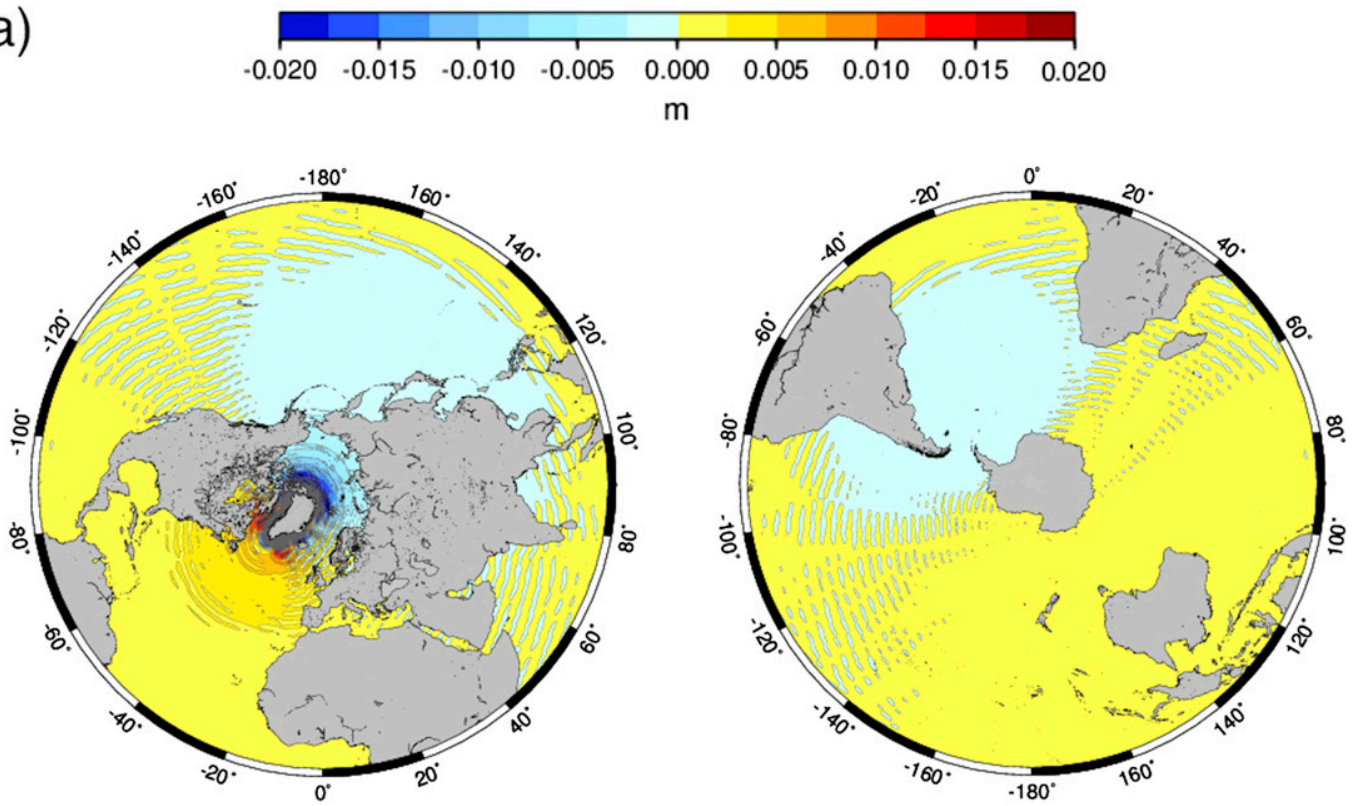

b)

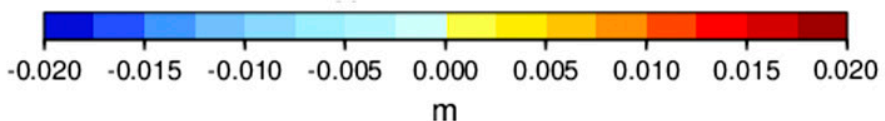

FIG. 8. As in Fig. 6, but for (a) differences between the RSL pattern estimated with Greenland SMB averaged and distributed uniformly over each drainage basin and the RSL pattern estimated with an equivalent total Greenland SMB distributed uniformly over the GrIS. (b) Differences between the RSL pattern estimated with a regional distribution of GrIS SMB changes at $1^{\circ}$ resolution and the RSL pattern estimated with Greenland SMB averaged and distributed uniformly over each drainage basin. In (a),(b), relative sea level patterns are computed as means of the RSL in 2080-99 (w.r.t. 1900-19) from the MAR reference simulation forced by the MIROC5 RCP4.5 simulation.

at regional scale over the twentieth and twenty-first centuries on the basis of 32 CMIP5 GCM simulations. This ensemble of SMB estimates compares well at decadal and multidecadal time scales with a MAR estimate based on the ERA-40 and ERA-Interim reanalyses over 1958-2014. However, the amplitude of the interannual variability of each ensemble member appears too small, particularly in basin 1 during the 2000s. Over the twentieth and twenty-first centuries the ensemble of SMB estimates shows a significant decrease in SMB in all basins as the climate warms. The projected Greenland SMB contribution to global mean sea level rise in 
2081-2100 is $+9.2 \pm 4.5 \mathrm{~cm}$ for the RCP8.5 scenario, which is within the range of the IPCC projections (3-16 cm in 2080-2100; see Church et al. 2013). This increase in SMB loss rates is marked by a substantial regional variability, confirming the importance of studying Greenland SMB at regional scale.

During the twentieth century, Greenland SMB is fairly stable except in basin 5 where it starts decreasing after 1950 because of increasing runoff anomalies exceeding the increasing snowfall anomalies. In the twenty-first century all basins show a decrease in SMB. It is particularly intense in basins 5 and 4 where snowfall increases remain small during the twenty-first century and do not compensate for the large increase in runoff anomalies. By the end of the twenty-first century, basin 5 SMB loss rate alone explains about $47 \%$ of the total GrIS SMB loss rate while both basin 4 and 5 SMB loss rates explain about $65 \%$ as they are more sensitive to the advection of warm air from the south. Basins 1, 2, 3, and 6 also show an increase in SMB loss rates, but they are smaller than in basins 4 and 5 because the increase in runoff anomalies is smaller and is partly compensated by a larger increase in snowfall anomalies.

Our results show that the GrIS SMB does not respond uniformly to GHG emissions. The southern part of the GrIS is more sensitive to climate warming and is in imbalance sooner than the northern part. This regional variability is important to take into account because it significantly affects the ice sheet dynamics and topography as well as the induced sea level fingerprints. Using a sea level equation model we show that the regional variability in projected GrIS SMB induces significant regional variability in projected sea level changes in large regions of the world. In most of the global ocean the RSL induced by the regional variability in Greenland SMB explains up to $10 \%-20 \%$ of the total local RSL associated with GrIS SMB changes. Along the U.S. East Coast and the north coast of Europe it explains up to $40 \%$ of the total local RSL. For this reason, we argue that the regional variability in Greenland SMB plays an important role in the regional variability in sea level rise and should be taken into account in sea level projections. A sensitivity study on the resolution of the Greenland SMB regional variability suggests that the basin-scale resolution is enough to resolve the associated RSL pattern with an accuracy of $5 \%$ in most of the ocean except in the Arctic and in small regions on the U.S. and European coasts.

Note that our results are probably conservative because the effects of ice sheet dynamics, ice sheet topography changes, the routing of surface water, and freshwater inputs on the ocean circulation are not taken into account. To go a step further and take these effects into account, we would need to couple the MAR regional climate model with an ice sheet model and dynamics model as well as with an ocean model.

Acknowledgments. Giorgio Spada is supported by DiSPeA Research Grant CUP H32I160000000005. The authors acknowledge the World Climate Research Programme's Working Group on Coupled Modelling, which is responsible for CMIP, and thank the climate modeling groups (models listed in Table 1 of this paper) for producing and making available their model output. For CMIP the U.S. Department of Energy's Program for Climate Model Diagnosis and Intercomparison provides coordinating support and led development of software infrastructure in partnership with the Global Organization for Earth System Science Portals. The authors thank the International Space Science Institute (ISSI; Bern, Switzerland) for support of the International Team on contemporary regional and global sea level rise. The authors also thank two anonymous reviewers and the editor for their constructive comments.

\section{REFERENCES}

Alexander, P. M., M. Tedesco, N.-J. Schlegel, S. B. Luthcke, X. Fettweis, and E. Larour, 2016: Greenland Ice Sheet seasonal and spatial mass variability from model simulations and GRACE (2003-2012). Cryosphere, 10, 1259-1277, doi:10.5194/ tc-10-1259-2016.

Belleflamme, A., X. Fettweis, C. Lang, and M. Erpicum, 2013: Current and future atmospheric circulation at $500 \mathrm{hPa}$ over Greenland simulated by the CMIP3 and CMIP5 global models. Climate Dyn., 41, 2061-2080, doi:10.1007/s00382-012-1538-2.

Box, J. E., D. H. Bromwich, and L. S. Bai, 2004: Greenland ice sheet surface mass balance 1991-2000: Application of polar MM5 mesoscale model and in situ data. J. Geophys. Res., 109 D16105, doi:10.1029/2003JD004451.

Church, J. A., and Coauthors, 2013: Sea level change. Climate Change 2013: The Physical Science Basis, T. F. Stocker et al., Eds., Cambridge University Press, 1137-1216, doi:10.1017/ CBO9781107415324.026.

Chylek, P., M. K. Dubey, and G. Lesins, 2006: Greenland warming of 1920-1930 and 1995-2005. Geophys. Res. Lett., 33, L11707, doi:10.1029/2006GL026510.

Colgan, W., J. E. Box, M. L. Andersen, X. Fettweis, B. Csatho, R. S. Faust, D. Van As, and J. Wahr, 2015: Greenland highelevation mass balance: Inference and implication of reference period (1961-90) imbalance. Ann. Glaciol., 56, 105-117, doi:10.3189/2015AoG70A967.

Dee, D. P., and Coauthors, 2011: The ERA-Interim reanalysis: Configuration and performance of the data assimilation system. Quart. J. Roy. Meteor. Soc., 137, 553-597, doi:10.1002/ qj.828.

Dziewonski, A., and D. Anderson, 1981: Preliminary Reference Earth Model. Phys. Earth Planet. Inter., 25, 297-356, doi:10.1016/0031-9201(81)90046-7.

Farrell, W. E., and J. A. Clark, 1976: On postglacial sea level. Geophys. J. Int., 46, 647-667, doi:10.1111/j.1365-246X.1976.tb01252.x. 
Fettweis, X., 2007: Reconstruction of the 1979-2006 Greenland ice sheet surface mass balance using the regional climate model MAR. Cryosphere, 1, 21-40, doi:10.5194/tc-1-21-2007.

$\longrightarrow$, H. Gallee, F. Lefebre, and J. P. van Ypersele, 2005: Greenland surface mass balance simulated by a regional climate model and comparison with satellite-derived data in 1990-1991. Climate Dyn., 24, 623-640, doi:10.1007/s00382-005-0010-y.

_- E. Hanna, H. Gallée, P. Huybrechts, and M. Erpicum, 2008: Estimation of the Greenland ice sheet surface mass balance for the 20th and 21st centuries. Cryosphere, 2, 117-129, doi:10.5194/tc-2-117-2008.

_- M. Tedesco, M. van den Broeke, and J. Ettema, 2011: Melting trends over the Greenland ice sheet (1958-2009) from spaceborne microwave data and regional climate models. Cryosphere, 5, 359-375, doi:10.5194/tc-5-359-2011.

_- B. Franco, M. Tedesco, J. H. van Angelen, J. T. M. Lenaerts, M. R. van den Broeke, and H. Gallée, 2013a: Estimating the Greenland ice sheet surface mass balance contribution to future sea level rise using the regional atmospheric climate model MAR. Cryosphere, 7, 469-489, doi:10.5194/ tc-7-469-2013.

_, E. Hanna, C. Lang, A. Belleflamme, M. Erpicum, and H. Gallee, 2013b: Important role of the mid-tropospheric atmospheric circulation in the recent surface melt increase over the Greenland ice sheet. Cryosphere, 7, 241-248, doi:10.5194/ tc-7-241-2013.

Franco, B., X. Fettweis, C. Lang, and M. Erpicum, 2012: Impact of spatial resolution on the modelling of the Greenland ice sheet surface mass balance between 1990-2010, using the regional climate model MAR. Cryosphere, 6, 695-711, doi:10.5194/ tc-6-695-2012.

- - , and M. Erpicum, 2013: Future projections of the Greenland ice sheet energy balance driving the surface melt. Cryosphere, 7, 1-18, doi:10.5194/tc-7-1-2013.

Goelzer, H., and Coauthors, 2013: Sensitivity of Greenland ice sheet projections to model formulations. J. Glaciol., 59, 733749, doi:10.3189/2013JoG12J182.

Gomez, N., J. Mitrovica, M. Tamisiea, and P. Clark, 2010: A new projection of sea level change in response to collapse of marine sectors of the Antarctic ice sheet. Geophys. J. Int., 180, 623-634, doi:10.1111/j.1365-246X.2009.04419.x.

Gregory, J. M., and P. Huybrechts, 2006: Ice-sheet contributions to future sea-level change. Philos. Trans. Roy. Soc. London, 364A, 1709-1731, doi:10.1098/rsta.2006.1796.

Hanna, E., and Coauthors, 2008: Increased runoff from melt from the Greenland ice sheet: A response to global warming. J. Climate, 21, 331-341, doi:10.1175/2007JCLI1964.1.

Howat, I. M., I. R. Joughin, and T. A. Scambos, 2007: Rapid changes in ice discharge from Greenland outlet glaciers. Science, 315, 1559-1561, doi:10.1126/science.1138478.

Kopp, R. E., J. X. Mitrovica, S. M. Griffies, J. Yin, C. C. Hay, and R. J. Stouffer, 2010: The impact of Greenland melt on local sea levels: A partially coupled analysis of dynamic and static equilibrium effects in idealized water-hosing experiments. $\mathrm{Cli}$ matic Change, 103, 619-625, doi:10.1007/s10584-010-9935-1.

Lefebre, F., H. Gallee, J. P. van Ypersele, and W. Greuell, 2003: Modeling of snow and ice melt at ETH Camp (West Greenland): A study of surface albedo. J. Geophys. Res., 108, 4231, doi:10.1029/2001JD001160.

, X. Fettweis, H. Gallee, J. P. Van Ypersele, P. Marbaix, W. Greuell, and P. Calanca, 2005: Evaluation of a highresolution regional climate simulation over Greenland. Climate Dyn., 25, 99-116, doi:10.1007/s00382-005-0005-8.
Lenaerts, J. T. M., M. R. van den Broeke, J. H. van Angelen, E. van Meijgaard, and S. J. Dery, 2012: Drifting snow climate of the Greenland ice sheet: A study with a regional climate model. Cryosphere, 6, 891-899, doi:10.5194/tc-6-891-2012.

D. Le Bars, L. van Kampenhout, M. Vizcaino, E. M. Enderlin, and M. R. van den Broeke, 2015: Representing Greenland ice sheet freshwater fluxes in climate models. $G e$ ophys. Res. Lett., 42, 6373-6381, doi:10.1002/2015GL064738.

Luo, H., R. M. Castelao, A. K. Rennermalm, M. Tedesco, A. Bracco, P. L. Yager, and T. L. Mote, 2016: Oceanic transport of surface meltwater from the southern Greenland ice sheet. Nat. Geosci., 9, 528-532, doi:10.1038/ngeo2708.

Milne, G. A., and J. X. Mitrovica, 1998: Postglacial sea-level change on a rotating Earth. Geophys. J. Int., 133, 1-19, doi:10.1046/j.1365-246X.1998.1331455.x.

— W. R. Gehrels, C. W. Hughes, and M. E. Tamisiea, 2009: Identifying the causes of sea-level change. Nat. Geosci., 2, 471478, doi:10.1038/ngeo544.

Mitrovica, J., M. Tamisiea, J. Davis, and G. Milne, 2001: Recent mass balance of polar ice sheets inferred from patterns of global sea-level change. Nature, 409, 1026-1029, doi:10.1038/35059054.

— , N. Gomez, and P. U. Clark, 2009: The sea-level fingerprint of West Antarctic collapse. Science, 323, 753, doi:10.1126/ science. 1166510 .

Moss, R. H., and Coauthors, 2010: The next generation of scenarios for climate change research and assessment. Nature, 463, 747756, doi:10.1038/nature08823.

Nick, F. M., A. Vieli, I. M. Howat, and I. Joughin, 2009: Large-scale changes in Greenland outlet glacier dynamics triggered at the terminus. Nat. Geosci., 2, 110-114, doi:10.1038/ngeo394.

Noel, B., W. J. van de Berg, E. van Meijgaard, P. K. Munneke, R. S. W. van de Wal, and M. R. van den Broeke, 2015: Evaluation of the updated regional climate model RACMO2.3: Summer snowfall impact on the Greenland ice sheet. Cryosphere, 9, 1831-1844, doi:10.5194/tc-9-1831-2015.

Rae, J. G. L., and Coauthors, 2012: Greenland ice sheet surface mass balance: Evaluating simulations and making projections with regional climate models. Cryosphere, 6, 1275-1294, doi:10.5194/tc-6-1275-2012.

Rignot, E., I. Velicogna, M. R. van den Broeke, A. Monaghan, and J. T. M. Lenaerts, 2011: Acceleration of the contribution of the Greenland and Antarctic ice sheets to sea level rise. Geophys. Res. Lett., 38, L05503, doi:10.1029/2011GL047109.

Sasgen, I., and Coauthors, 2012: Timing and origin of recent regional ice-mass loss in Greenland. Earth Planet. Sci. Lett., 333334, 293-303, doi:10.1016/j.epsl.2012.03.033.

Schuenemann, K. C., and J. J. Cassano, 2010: Changes in synoptic weather patterns and Greenland precipitation in the 20th and 21 st centuries: 2 . Analysis of 21 st century atmospheric changes using self-organizing maps. J. Geophys. Res., 115, D05108, doi:10.1029/2009JD011706.

Shannon, S. R., and Coauthors, 2013: Enhanced basal lubrication and the contribution of the Greenland ice sheet to future sealevel rise. Proc. Natl. Acad. Sci. USA, 110, 14156-14161, doi:10.1073/pnas.1212647110.

Shepherd, A., and Coauthors, 2012: A reconciled estimate of icesheet mass balance. Science, 338, 1183-1189, doi:10.1126/ science. 1228102.

Spada, G., and P. Stocchi, 2007: SELEN: A Fortran 90 program for solving the "sea-level equation." Comput. Geosci., 33, 538562, doi:10.1016/j.cageo.2006.08.006.

D. Melini, G. Galassi, and F. Colleoni, 2012: Modeling sea level changes and geodetic variations by glacial isostasy: The 
improved SELEN code. ArXiv preprint arXiv:1212.5061, 37 pp. [Available online at https://arxiv.org/abs/1212.5061.]

Stammer, D., 2008: Response of the global ocean to Greenland and Antarctic ice melting. J. Geophys. Res., 113, C06022, doi:10.1029/2006JC004079.

Sundal, A. V., A. Shepherd, P. Nienow, E. Hanna, S. Palmer, and P. Huybrechts, 2011: Melt-induced speed-up of Greenland ice sheet offset by efficient subglacial drainage. Nature, 469, 521524, doi:10.1038/nature09740.

- _ - M. van den Broeke, J. Van Angelen, N. Gourmelen, and J. Park, 2013: Controls on short-term variations in Greenland glacier dynamics. J. Glaciol., 59, 883-892, doi:10.3189/2013JoG13J019.

Tamisiea, M., and J. Mitrovica, 2011: The moving boundaries of sea level change: Understanding the origins of geographic variability. Oceanography, 24, 24-39, doi:10.5670/oceanog.2011.25.

Taylor, K. E., R. J. Stouffer, and G. A. Meehl, 2012: An overview of CMIP5 and the experiment design. Bull. Amer. Meteor. Soc., 93, 485-498, doi:10.1175/BAMS-D-11-00094.1.

Tedesco, M., and X. Fettweis, 2012: 21st century projections of surface mass balance changes for major drainage systems of the Greenland ice sheet. Environ. Res. Lett., 7, 045405, doi:10.1088/1748-9326/7/4/045405.
Uppala, S. M., and Coauthors, 2005: The ERA-40 Re-Analysis. Quart. J. Roy. Meteor. Soc., 131, 2961-3012, doi:10.1256/qj.04.176.

van den Broeke, M., and Coauthors, 2009: Partitioning recent Greenland mass loss. Science, 326, 984-986, doi:10.1126/ science.1178176.

—, E. M. Enderlin, I. M. Howat, P. Kuipers Munneke, B. P. Y. Noël, W. J. van de Berg, E. van Meijgaard, and B. Wouters, 2016: On the recent contribution of the Greenland ice sheet to sea level change. Cryosphere, 10, 1933-1946, doi:10.5194/ tc-10-1933-2016.

Vizcaíno, M., W. H. Lipscomb, W. J. Sacks, and M. van den Broeke, 2014: Greenland surface mass balance as simulated by the Community Earth System Model. Part II: Twenty-firstcentury changes. J. Climate, 27, 215-226, doi:10.1175/ JCLI-D-12-00588.1.

— U. Mikolajewicz, F. Ziemen, C. B. Rodehacke, R. Greve, and M. R. van den Broeke, 2015: Coupled simulations of Greenland ice sheet and climate change up to A.D. 2300. Geophys. Res. Lett., 42, 3927-3935, doi:10.1002/2014GL061142.

Zwally, H. J., W. Abdalati, T. Herring, K. Larson, J. Saba, and K. Steffen, 2002: Surface melt-induced acceleration of Greenland ice-sheet flow. Science, 297, 218-222, doi:10.1126/ science. 1072708 . 